\title{
RELATIONS BETWEEN TORSION PROPERTIES AND HISTOLOGY OF ADULT HUMAN COMPACT BONE*†
}

\author{
F. GAYNOR EVANS \\ Department of Anatomy, The University of Michigan. Ann Arbor, MI 48109. U.S.A.
}

\begin{abstract}
Torsion properties and the histological composition of cross sections a: the fracture site were determined for 123 standardized specimens of compact bone from various thirds and sides of the shaft of 28 femurs from adult embalmed dissecting room cadavers. Sufficient unembalmed material was unavailable Statistically significant differences were found between the means for torsion properties and for histologica! composition of specimens from various regions of the bone. Significant correlation coefficients were found between the various torsion properties of the specimens and the histological components in the break area The implications of these correlations are that torsion shear stress, shear modulus, and energy absorbed to failure tend to be increased by the number or percentage of complete osteons in the break area. Shear modulus tends to be increased, to a lesser extent. by the percentage of interstitial lamellae in the break area. All torsion properties tend to be reduced by the percentage of spaces in the break area. Shear stress and modulus also tend to be reduced by the percentage of osteon fragments in the break area.
\end{abstract}

\section{IYTRODUCTION}

The present investigation is one in a continuing series of studies on the interrelations between various mechanical properties and histological components of standardized specimens of human compact bone. In previous studies (Evans and Bang, 1966, 1967; Evans, 1973: Evans and Vincentelli, 1974; Abdelnour and Evans, 1976: Evans, 1976) relations between the tensile. compressive, and single (punching) shearing properties as well as fatigue life of human compact bone (Evans and Riolo, 1970) and its histological composition were investigated.

The torsion properties of standardized specimens of human compact bone were first determined by Rauber (1876) and later by Hazama (1956). Recently, Knets et al. (1973) and Pfafrod et al. $(1972,1975)$ reported regional, directional, and age differences in the torsional shear stress and modulus of standardized specimens of human tibial compact bone.

Knets et al. related the torsion properties of human compact bone to the concentration of certain biochemical substances in the bone while Pfafrod et al. related them to age changes in the degree of mineralization and porosity of the bone.

In the reviews by Kraus (1968) and by Currey (1970) the torsion properties of human compact bone are not discussed, but Reilly and Burstein (1974) illustrate a torsion fracture of a standardized specimen of compact bone.

The present investigation was undertaken to determine if there are significant regional differences in

* Receiced 4 October 1977.

+ This research was supported (in part) by Research Grant AM-03865 from the National Institutes of Health, Department of Health, Education and Welfare. and correlations between the torsion properties and histological components of standardized specimens of compact bone from adult human femurs. Data obtained in this study may also contribute to a better understanding of the mechanics of torsion fractures which are quite frequent in long bones.

\section{MATERIALS IND METHODS}

The material used in the present investigation consisted of 123 standardized torsion specimens from 28 fernurs ( 12 men and 2 women) from dissecting room cadavers. One man and one woman were Negroes but the rest were Caucasians. All femurs appeared to be normal and none were taken from individuals who had died from a primary bone disease or one during which the subject would have been bedridden for a long time prior to death. The subjects varied from 44 to 85 years of age with an average age of $65.5 \mathrm{yr}$. Embalmed bones were used because a sufficient number of intact unembalmed femurs were not available.

Torsion test specimens were machined to a standardized size and shape from the compact bone of the anterior, the anterolateral, the lateral, the posterior. the medial, and the anteromedial sides of the proximal. the middle and the distal thirds of the femoral shaft. The test specimens (Fig. 1) were cylinders 1.25 in. long

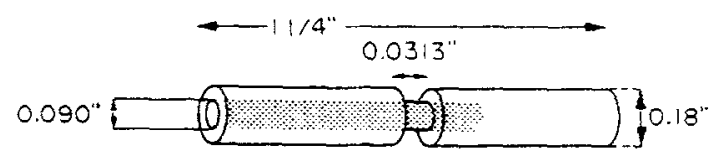

Fig. 1. Standardized torsion test specimens of adult human femoral compact bone (From Evans, F. G., Mechanical

Properties of Bone. Charles C. Thomas, Springfield). 
and 0.18 in. in dia. A central hole 0.090 in. in dia. extended through $75 \%$ the length of the specimen. A rectangular groove 0.0313 in. wide encircled the middle of the specimen. The walls of the specimen in the floor of the groove had a uniform thickness of $0.15 \mathrm{in}$. The function of the groove was to concentrate the stresses in that area so that failure would occur there. It also minimized the effect of tensile stresses and thus increased the probability that failure of the specimen would occur from torsional shearing stresses.

During preparation of the specimens care was taken to prevent overheating and drying. After the specimens were prepared they were stored in a physiological saline solution until tested which was done while the specimen was in the moist condition. The cross sectional dimensions of the specimen were measured with calipers before and after testing to determine if swelling had occurred.

A special torsion apparatus (Fig. 2) was fabricated for testing the specimens. The apparatus consisted of a wheel and two sets of jaws, placed in the axis about which the wheel rotated, to hold the specimens while being tested. One set of jaws was fixed while the other set rotated with the wheel. A torsion force was applied slowly to the specimen, by placing weights of known magnitude in a pan suspended by a thread wrapped around the rim of the wheel, until failure of the specimen occurred. The axis about which torsion occurred passed longitudinally through the center of the specimen. The angle (degrees) through which the specimen twisted during a test was read directly from graduated marks, based on a protractor mounted on the external surface of the wheel. Ultimate failure of the specimen occurred in the groove encircling the middle of the specimen. The fracture was in a flat plane normal to the long axis of the specimen and did not spiral around the long axis.

From the data obtained in a test a torque vs angle of twist curve was drawn for each specimen. From this curve the shear modulus of elasticity $(G)$, ultimate torsion stress, and energy absorbed to failure were calculated. Ultimate torsion stress (strength) and shear modulus were calculated in $\mathrm{Pa}$. Energy absorbed to failure $\left(\mathrm{J} / \mathrm{mm}^{2}\right)$ was determined by measuring the area beneath the curve with a compensating polar planimeter.

Cross sections of the specimens, taken as close as possible to the fracture site, were ground to a thickness of $70 \mu \mathrm{m}$, mounted on a slide, and photographed in ordinary light with a Zeiss photomicroscope. Prints of the photomicrographs, enlarged to a standardized size, were then made on photographic paper of a known weight. Since the weight of a given area of the paper was known, a conversion factor was calculated so that paper weight $(\mathrm{gm})$ could be converted into area $\left(\mathrm{mm}^{2}\right)$. The enlarged print of the cross section, which was a flat ring, was used for calculating the percentage of the cross sectional area formed by secondary osteons, fragments (remnants) of secondary osteons, interstitial lamellae, and spaces (lacunae and canaliculi excluded).
The analysis was made by cutting out the intact cross section, weighing it and then computing its cross sectional area. Then the various histological components of the cross section were cut out, weighed, and their area calculated. From this data the percentage of the cross sectional area formed by each of the histological components was computed. All the histological analyses were made by the same person and the original slide was in the microscope for reference to clear up any questions regarding identification of the individual components.

The torsional property and histological data were then subjected to an analysis of variance to determine if there were any statistically significant differences between the mean values for torsion properties and various histological components of specimens from different regions of the femoral shaft. Coefficients of correlation between the various torsion properties and histological components of the break area were computed to determine if any of the relations between the variables were statistically significant. These analyses were made on computers in the University of $\mathrm{Mi}$ chigan Statistical Research Laboratory after consultation with members of the laboratory staff.

\section{RESULTS}

\section{Mechanical properties (Table 1)}

Torsional shear stress. Analysis of the data according to the third of the femoral shaft from which the specimens were obtained revealed that the specimens from the middle third had the maximum $(51.2 \pm 1.3 \mathrm{MPa})$ and those from the distal third the minimal $(44.9 \pm 3.3 \mathrm{MPa})$ mean shearing stress.

When the data were analyzed with respect to the side of the shaft from which the specimens came it was found that the medial side specimens had the highest $(53.0 \pm 1.6 \mathrm{MPa})$ and the anterolateral side specimens the lowest mean $(39.8 \pm 2.6 \mathrm{MPa})$ shearing stress. However, the difference between the means for medial side specimens was only 0.01 greater than that for the lateral side specimens.

Shear modulus. Mean shear modulus was greatest $(7.98 \pm 0.38 \mathrm{GPa})$ in middle third and least $(6.46 \pm 0.75 \mathrm{GPa})$ in distal third specimens. Medial side specimens had the highest $(8.44 \pm 0.45 \mathrm{GPa})$ and anterolateral side specimens the lowest $(5.50 \pm 0.61 \mathrm{GPa})$ mean shear modulus. Differences between the highest and the lowest mean values for shear modulus of specimens from various thirds and sides of the femur were greater than those for shear stress.

Energy absorbed to failure. Topographic differences were also found in the amount of energy absorbed to failure by specimens from various regions of the femur. Middle third specimens absorbed the most $\left(540 \pm 16 \mathrm{~kJ} / \mathrm{m}^{2}\right)$ mean energy to failure while the least $\left(460 \pm 35 \mathrm{~kJ} / \mathrm{m}^{2}\right)$ was absorbed by distal third specimens. As far as the sides of the bone were concerned, 

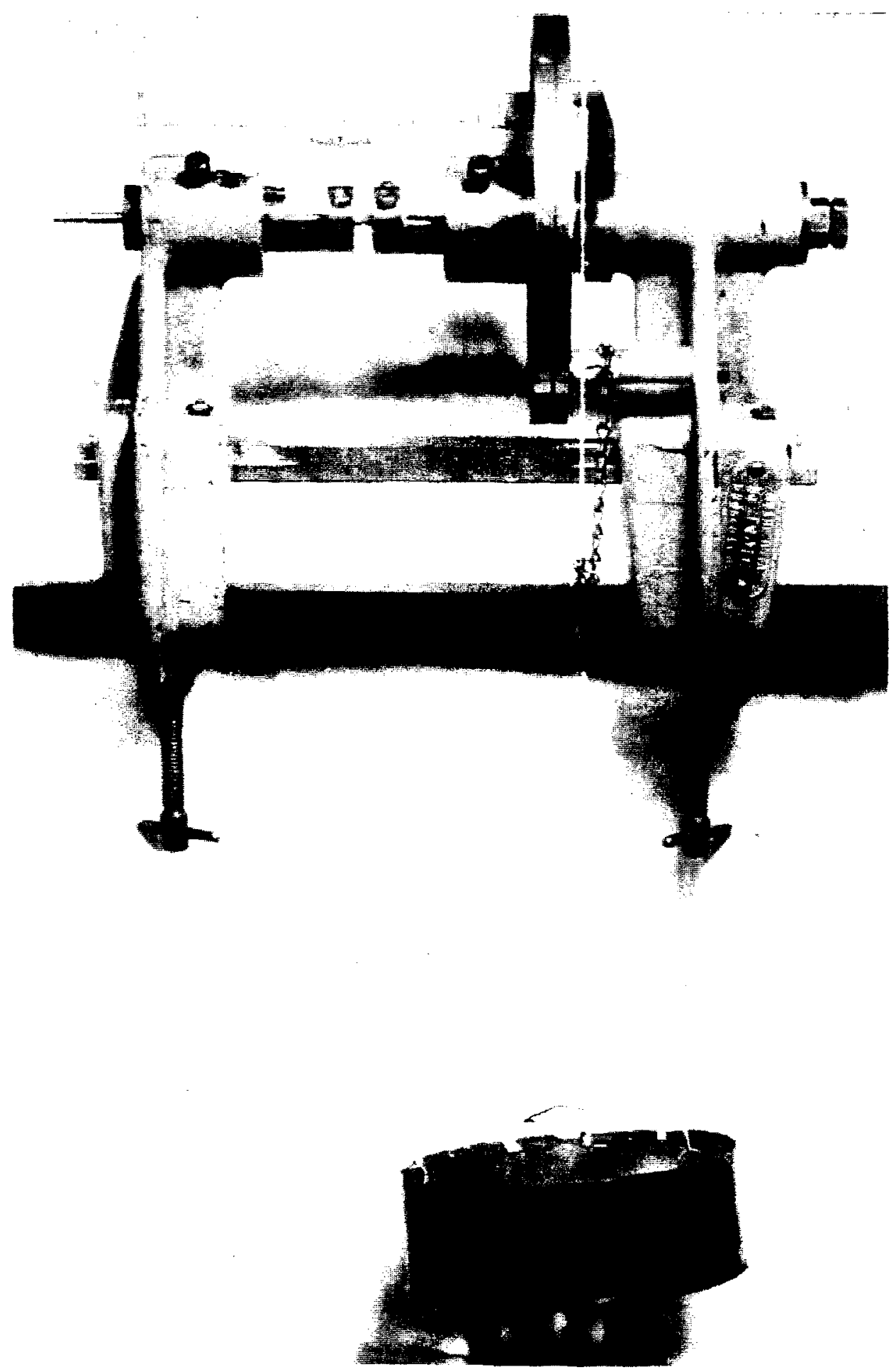

Fig. 2. Jig for torsion testing. (From Evans, F. G., Mechanical

Properties of Bone. Charles C. Thomas, Springfield). 
the lateral side specimens had the highest $\left(570=24 \mathrm{~kJ} / \mathrm{m}^{2}\right)$ and the anterolateral side ones the lowest $\left(420 \pm 35 \mathrm{~kJ} / \mathrm{m}^{2}\right)$ mean energy absorbed to failure. However, the energy absorbed to failure by the lateral side specimens was only 0.1 greater than that absorbed by the medial side specimens.

Body side differences. Comparison of the torsion properties of specimens from the right and the left fernurs showed that mean shear modulus, shear stress, and energy absorbed to failure were all greater in specimens from the left than in those from the right femur.

Histological structure (Table 2). Topographic differences, according to the region of the bone from which the specimens were taken, were found in the mean percentage of the break area formed by various histological components as well as the mean numbers of the various histological components in the break area.

Percentage of spaces. Analyzing the specimens from different thirds of the bone showed that the mean percentage of spaces (Haversian canals, resorption areas, etc.) in the break area was highest $(6.4 \pm 0.5)$ in middle third specimens and lowest $(4.6 \pm 0.5)$ in distal third specimens.

Differences were also found with respect to the side of the bone from which the specimens were obtained. Posterior side specimens had the largest $(7.8 \pm 1.2)$ and lateral side specimens the smallest $(5.2 \pm 0.5)$ mean percentage of spaces.

Percentage of fragments of secondary osteons. The highest mean percentage of fragments of secondary osteons $(24.9 \pm 1.3)$ was found in specimens from the proximal and lowest $(19.4 \pm 1.1)$ in those from the middle third of the bone. Specimens from the anterior side had the highest mean percentage $(24.4 \pm 1.8)$ of fragments while those from the posterior side had the lowest mean percentage $(20.1 \pm 2.3)$.

Percentage of complete secondary osteons. When analyzed according to third of the bone from which the specimens were taken, it is found that middle third specimens had the highest $(36.4 \pm 1.0)$ and distal third specimens the lowest $(32.1 \pm 1.7)$ mean percentage of complete secondary osteons.

Variation according to the side of the bone from which the specimen was obtained revealed that the highest $(38.5 \pm 1.6)$ and the lowest $(31.7 \pm 1.5)$ mean percentage of complete secondary osteons were found in lateral side and in anterior side specimens. respectively.

Percentage of interstitial lamellae. Distal third specimens had the highest $(41.9 \pm 2.5)$ and proximal third specimens the lowest $(33.6 \pm 1.7)$ mean percentage of interstitial lamellae.

Anteromedial side specimens were found to have the highest $(39.1 \pm 2.5)$ and lateral side specimens the lowest $(32.7 \pm 2.1)$ mean percentage of interstitial lamellae when the data were analyzed according to the side from which the specimens were taken.

Number of fragments of secondary osteons. Classifying the data according to the third of the bone from which the specimens were taken showed that those from the proximal third had the highest (122) and those from the distal third the lowest (96) mean number of fragments of secondary osteons.

A similar analysis according to the side of the bone from which the specimen was taken revealed that the mean number of osteon fragments was highest $(123)$ in specimens from the anterior side and lowest (97) in specimens from the anterolateral side, respectively.

Number of complete secondary asteons. Comparison of specimens by thirds shows that the middle third specimens had the highest (152) mean number of complete secondary osteons and the distal third specimens had the lowest (124). The mean number of complete osteons, according to bone side, was highest (161) and lowest (132) in the lateral side specimens and posterior side specimens respectively.

\section{STATISTICAL ANALYSIS}

The data obtained in the study were subjected to a statistical analysis to determine if there were any significant differences between the means of both torsion properties and histological components of specimens from different regions of the bone. In all cases, the significance had to be at or better than the 0.05 level to be considered.

\section{Torsion properties (Table 1)}

An analysis of variance revealed some statistically significant differences between the mean torsion pro-

Table 1. Topographic differences in mean and standard error of torsion properties of standardized hollow cylindrical specimens of compact bone from embalmed adult human femurs

\begin{tabular}{|c|c|c|c|c|}
\hline Region & No. & $\begin{array}{l}\text { Shear stress } \\
\text { (MPa) }\end{array}$ & $\begin{array}{l}\text { Shear modulus } \\
\qquad(\mathrm{GPa})\end{array}$ & $\begin{array}{l}\text { Energy absorbed } \\
\text { to failure }\left(\mathrm{kJ} / \mathrm{m}^{2}\right)\end{array}$ \\
\hline Proximal third & 52 & $46.6 \pm 1.4$ & $6.63 \pm 0.31$ & $498 \pm 22$ \\
\hline Middle third & 54 & $51.2 \pm 1.3$ & $7.98 \pm 0.38$ & $540 \pm 16$ \\
\hline Distal third & 17 & $44.9 \pm 3.3$ & $6.46 \pm 0.75$ & $460 \pm 35$ \\
\hline Lateral side & 18 & $52.9 \pm 1.8$ & $7.56 \pm 0.67$ & $570 \pm 24$ \\
\hline Ant. lat. sıde & 14 & $39.8 \pm 2.6$ & $5.50 \pm 0.61$ & $420 \pm 35$ \\
\hline Ant. side & 26 & $46.2 \pm 2.1$ & $6.65 \pm 0.52$ & $480 \pm 26$ \\
\hline Ant med. side & 17 & $44.8 \pm 2.3$ & $6.85 \pm 0.64$ & $470 \pm 32$ \\
\hline Medial side & 28 & $53.0 \pm 1.6$ & $8.44 \pm 0.45$ & $560 \pm 31$ \\
\hline Posterior side & 20 & $50.0 \pm 2.7$ & $7.33 \pm 0.62$ & $520 \pm 30$ \\
\hline
\end{tabular}


perties of specimens from different thirds of the femoral shaft.

Mean torsional shear stress of specimens from the middle third of bone was significantly greater ( $P$ $<0.030$ ) than that of specimens from the distal third of the bone. Middle third specimens also had a mean shear strength significantly greater $(P<0.038)$ than that of specimens from the proximal third of the bone.

Mean shear modulus of specimens from the middle third of the bone was significantly greater $(P<0.025)$ than that of specimens from the proximal third of the bone.

No significant differences were found between the mean energy absorbed to failure by specimens from various thirds of the bone.

Significant differences were also found between the means for the torsion properties of specimens from different sides of the femoral shaft. Thus, mean torsional shear stress of specimens from the medial and from the lateral sides were both significantly greater ( $P$ $<0.025$ ) than that of specimens from the anterior, the anterolateral and the anteromedial sides of the bone. Posterior side specimens also had a mean torsional shear stress greater, at the same significance level, than that of anterolateral side specimens.

Medial side specimens had a mean shear modulus significantly greater $(P<0.025)$ than that of specimens from the anterior and from the anterolateral sides. No other significant differences were found in the mean shear modulus.
Mean energy absorbed to failure of lateral and of medial side specimens was significantly greater $(P$ $<0.025$ ) than that of anterior, anterolateral, and the anteromedial specimens.

\section{Histological components (Table 2)}

Some significant differences were also found between the mean percentage of the break area formed by various histological components in specimens from various regions of the bone. In proximal third specimens the mean percentage of the break area formed by osteon fragments was significantly greater $(P<0.010)$ than that of middle third specimens. The mean percentage of interstitial lamellae in the break area was statistically greater $(P<0.025)$ in specimens from the distal than in those from the proximal third of the bone.

When the data were analyzed with respect to the side of the shaft of the bone from which the specimens were obtained the only significant differences were in the mean number of complete osteons in the break area of the lateral and of medial side specimens, which was significantly greater $(P<0.025)$ than that of anterior side specimens.

\section{Coefficients of correlation (Table 3)}

Coefficients of correlation between the torsion properties and histological components of the break area of the specimens revealed several significant relations.

Table 2. Topographic differences in the mean and standard error of the percentages and number of histological components of the break area of standardized hollow cylindrical specimens of compact bone from embalmed adult human femurs

\begin{tabular}{|c|c|c|c|c|c|c|c|}
\hline \multirow[b]{2}{*}{ Regions } & \multicolumn{4}{|c|}{ Percentage of break area } & \multicolumn{3}{|c|}{ Total aumber in break area } \\
\hline & No. & $\begin{array}{l}\text { Spaces } \\
\text { (Holes) }\end{array}$ & $\begin{array}{c}\text { Osteon } \\
\text { fragments }\end{array}$ & $\begin{array}{l}\text { Complete } \\
\text { osteons }\end{array}$ & $\begin{array}{l}\text { Interstitial } \\
\text { lamellae }\end{array}$ & $\begin{array}{c}\text { Osteen } \\
\text { Iragmetis }\end{array}$ & $\begin{array}{l}\text { Complete } \\
\text { osteons }\end{array}$ \\
\hline $\begin{array}{l}\text { Proximal third } \\
\text { :iddle third } \\
\text { Distal third } \\
\text { Lateral side } \\
\text { Ant. lat. side } \\
\text { Anterior side } \\
\text { Ant. med. side } \\
\text { Medial side } \\
\text { Posterior side }\end{array}$ & $\begin{array}{l}52 \\
54 \\
17 \\
18 \\
14 \\
26 \\
17 \\
28 \\
20\end{array}$ & $\begin{array}{l}6.3 \pm 0.5 \\
6.4 \pm 0.5 \\
4.6 \pm 0.5 \\
5.2 \pm 0.5 \\
6.1 \pm 0.7 \\
6.5 \pm 0.6 \\
5.4 \pm 0.5 \\
5.4 \pm 0.5 \\
7.8 \pm 1.2\end{array}$ & $\begin{array}{l}24.9 \pm 1.3 \\
19.4 \pm 1.1 \\
20.9 \pm 1.6 \\
23.5 \pm 1.8 \\
20.9 \pm 1.9 \\
24.4 \pm 1.8 \\
20.7 \pm 1.9 \\
21.8 \pm 1.6 \\
20.1 \pm 2.3\end{array}$ & $\begin{array}{l}34.9 \pm 1.0 \\
36.4 \pm 1.0 \\
32.1 \pm 1.7 \\
38.5 \pm 1.6 \\
36.4 \pm 1.6 \\
31.7 \pm 1.5 \\
34.8 \pm 1.8 \\
37.1 \pm 1.7 \\
33.7 \pm 1.4\end{array}$ & $\begin{array}{l}33.6 \pm 1.7 \\
37.5 \pm 1.4 \\
41.9 \pm 2.5 \\
32.7 \pm 2.1 \\
36.6 \pm 2.2 \\
36.7 \pm 2.4 \\
39.1 \pm 2.5 \\
35.7 \pm 2.2 \\
38.4 \pm 3.1\end{array}$ & $\begin{aligned} 123 & \doteq 6 \\
103 & =9 \\
96 & \pm 5 \\
119 & =11 \\
97 & =11 \\
123 & =13 \\
107 & =13 \\
109 & =9 \\
100 & =13\end{aligned}$ & $\begin{array}{l}138=6 \\
152 \pm 5 \\
124 \div 6 \\
161=10 \\
141=6 \\
134 \pm 10 \\
147 \pm 11 \\
144=6 \\
132=7\end{array}$ \\
\hline
\end{tabular}

Table 3. Correlations between torsion properties and histological components of 123 standardized hollow cylindrical specimens of embalmed compact bone from 28 adult human femurs

\begin{tabular}{|c|c|c|}
\hline $\begin{array}{l}\text { Variables } \\
\text { Torsion properties and histology of break area }\end{array}$ & Correlation coefficient $(R)$ & Significance level \\
\hline Torsion shear stress vs $\%$ spaces & -0.4187 & $>0.01$ \\
\hline Torsion shear stress vs number of complete secondary osteons & 0.2804 & $>0.01$ \\
\hline Torsion shear stress vs $\%$ of osteon fragments & -0.2010 & $>0.05$ \\
\hline Torsion shear vs $\%$ of complete osteons & 0.2258 & $>0.05$ \\
\hline Shear modulus vs \% spaces & -0.4179 & $>0.01$ \\
\hline Shear modulus vs \% osteon fragments & -0.1816 & $>0.05$ \\
\hline Shear modulus vs \% interstitial lamellae & 0.2196 & $>0.05$ \\
\hline Shear modulus vs number of complete osteons & 0.3429 & $>0.01$ \\
\hline Energy absorbed to failure vs \% spaces & -0.3532 & $>0.01$ \\
\hline Energy absorbed to failure vs omplete osteons & 0.2455 & $>0.01$ \\
\hline Energy absorbed to failure vs number of complete osteons & 0.2244 & $>0.05$ \\
\hline
\end{tabular}


At the 0.01 significance level torsional shear stress had a positive correlation with the number of complete secondary osteons and a negative correlation with the percentage of spaces in the break area. At the 0.05 significance level shear stress had a positive correlation with the percentage of complete osteons and a negative correlation with the percentage of osteon fragments in the break area.

Shear modulus had, at the 0.01 significance level, a positive correlation with the total number of complete osteons and a negative correlation with the percentage of spaces in the break area. At the 0.05 significance level modulus had a positive correlation with the percentage of interstitial lamellae and a negative correlation with the percentage of osteon fragments in the break area.

At the 0.01 significance level energy absorbed to failure had a positive correlation with the percentage of complete osteons and a negative correlation with the percentage of spaces in the break area. A positive correlation, at the 0.05 significance level, was found between energy absorbed to failure and the number of complete osteons in the break area.

\section{Discussion}

The mean value for torsion shear stress and for shear modulus of all 123 specimens, regardless of the region of the bone from which they were obtained, used in the present study was lower and higher, respectively, than that reported by previous investigators (Table 4). These differences may be due to variations in the bone (humerus, femur, tibia) from which the test specimens were obtained, conditions of the specimens tested (embalmed or unembalmed; wet or dry), number of specimens tested, testing methods, type of specimens tested (solid cylindrical rods, square plates, tubular cylinders), long axis of the test specimen with respect to that of the intact bone, age of the individual from whom the specimens were obtained, plus histological and biochemical composition of the bone.

Although the compressive properties of human and bovine compact bone are rate sensitive (McElhaney and Byars, 1965), the variations found by different investigators in the torsion properties of human compact bone are probably not the result of great differences in loading speed which was generally rather slow. Pfafrod et al. (1975) loaded their torsion specimens at a rate of $0.111 \mathrm{rad} / \mathrm{min}$ but the other investigators (Table 4) did not record the exact loading speed used in their studies.

Perhaps the most influential factor. as far as the lower mean torsion stress found in the present study is concerned, was the average age ( $65.5 \mathrm{yr}$ ) of the subjects from whom the specimens are obtained. According to Pfafrod et al. (1975) torsion strength is maximum between 25 and 35 years of age after which it gradually declines. Yamada (1970) reported that the modulus of elasticity in torsion of human compact bone also decreased with age whereas the mean shear modulus found in the present study was greater than that reported by previous investigators. This may be due to the type of specimens tested in the present study.

Tubular cylindrical specimens with walls of uniform thickness, as in the region of the groove encircling the specimens used in the present study, are preferred for torsion tests because the torsion force is more uniformly distributed over the cross sectional area of a tubular specimen than it is when other types of specimens, e.g. solid cylinders, are tested (Richards, 1961). The groove encircling the specimens used in the present study eliminated or minimized the effect of tensile stresses in the region so that failure presumably occurred from torsional shearing stress.

Data obtained for torsion tests of hollow cylindrical specimens with walls of uniform thickness probably represent more accurate values for the torsion properties of a material than those obtained from torsion tests with other types of specimens. Tubular cylinders with

Table 4. Torsional shearing stress and modulus in the long axis of standardized specimens of adult human compact bone as reported by different investigators

\begin{tabular}{|c|c|c|c|c|c|c|}
\hline Author & Bone & $\begin{array}{l}\text { No. of } \\
\text { specimens }\end{array}$ & Subject & $\begin{array}{l}\text { Specimen condition } \\
\text { and form }\end{array}$ & $\begin{array}{c}\text { Torsional shear } \\
\text { stress } \\
\left(\times 10^{2} \mathrm{~Pa}\right)\end{array}$ & $\begin{array}{l}\text { Shear modulus } \\
\qquad\left(\times 10^{9} \mathrm{~Pa}\right)\end{array}$ \\
\hline Rauber (1876) & Humerus & 4 & 30 yr M & $\begin{array}{l}\text { Fresh, solid } \\
\text { cylindrical rods }\end{array}$ & 7.674 & \\
\hline Hazama (1956) & Fernur & 22 & $\begin{array}{l}22 \text { subjects } \\
(20-80 \mathrm{yr})\end{array}$ & $\begin{array}{l}\text { Fresh, solid } \\
\text { cylindrical rods }\end{array}$ & $5.305 \pm 0.058$ & 3.14 \\
\hline \multirow[t]{3}{*}{$\begin{array}{l}\text { Pfafrod et al. } \\
\text { (1972) }\end{array}$} & Tibia & 7 & $37 \mathrm{yr}$ & $\begin{array}{l}\text { Fresh, solid } \\
\text { cylindrical rods }\end{array}$ & & $5.00 \pm 0.196$ \\
\hline & Tibia & 7 & $27 \mathrm{yr}$ & $\begin{array}{l}\text { Fresh, square } \\
\text { plates }\end{array}$ & & $4.50=0.029$ \\
\hline & Tibia & 7 & $47 \mathrm{yr}$ & Fresh, square & & $5.19 \pm 0.98$ \\
\hline $\begin{array}{l}\text { Pfafrod et al. } \\
(1975)\end{array}$ & Tibia & $?$ & & $\begin{array}{l}\text { Fresh, solid } \\
\text { cylindrical rod }\end{array}$ & 10.34 & \\
\hline $\begin{array}{l}\text { Evans } \\
\text { (present study) }\end{array}$ & Femur & 123 & $\begin{array}{l}44-85 \mathrm{yr} \\
\text { (avg 65.5) }\end{array}$ & $\begin{array}{l}\text { Embalmed, wet } \\
\text { tubular cylinders }\end{array}$ & 4.84 & 7.17 \\
\hline
\end{tabular}


thinner walls, in proportion to the radius, than in our specimens would have an even more uniform distribution of the torsion stress over the cross sectional area of the specimen.

It is interesting to note that the middle third specimens had the maximum mean value for all the variables in the present investigation except for the percentage of osteon fragments and of interstitial lamellae, as well as the total number of osteon fragments in the break area (Table 5). Distal third specimens had the minimal mean values for all the variables except for the percentage of osteon fragments and of interstitial lamellae in the break area. However, no specimens from one side of the femur had the mean maximal or minimal values for the variables in the majority of cases.

The relations suggested by comparison of the regions with maximum and minimum values for torsion properties and histological components of the cross sections (Table 5) implies a causal relation between the two sets of variables. This idea was further enhanced by the finding of several highly significant correlation coefficients between the torsion properties and the histological composition of the specimens (Table 3 ). Although significant correlation coefficients between two phenomena do not prove a cause and effect relationship between them, they suggest that the relationship is due to something more than chance.

Pfafrod et al. (1975) in their study of the torsion strength of circular rods. whose long axis was parallel with the orientation of the osteons, found microfractures that traversed all the articulated parts of an osteon. Occasionally slight fragmentation of separate osteon plates or a falling out of whole segments occurred. Sometimes many microfractures were seen in the osteonic lamellae and connective plates which resulted in zones of many small fragments traversed by the fracture plane.

From their studies Pfafrod et al. concluded that the direction and form of the torsion fracture was dependent upon the direction of the load relative to the orientation of the osteons. However, they were unable to determine precisely in which structural part of the section the microfracture produced by torsion first appeared.

The only fractures seen in our cross sections were those accidentally produced while grinding the sections to the desired thickness $(70 \mu \mathrm{m})$ for photo- micrography. Sometimes the fracture traversed the entire cross section without displacing the two parts but more often two or three fragments were broken out of the cross section. Occasionally the fracture line exhibited a tendency to follow the cement lines but usually it passed straight through the section regardless of its various histological components.

The implications of the correlation coefficients between the torsion properties and histological components of human compact bone (Table 3) are that torsional shear stress, shear modulus, and energy absorbed to failure are all increased by secondary osteons but decreased by spaces in the bone. To a less significant extent the presence of interstitial lamellac also increases the shear modulus of human compact bone. However, osteons, because of their Haversian canals, lacunae and canaliculi, also weaken a bone by reducing the amount of osseous tissue available for supporting or resisting a load. Haversian canals play a greater role in reducing the strength of compact bone than do lacunae and canaliculi which, according to Frost (1960), together constitute only $2.28 \%$ of vascular-free compact bone volume of human long bones. Consequently, it is felt that the exclusion of the area and/or percentage of the lacunae and canaliculi in the histological analysis of the cross sections of the specimens used in the present study does not significantly influence its results.

Implications of the influence of various histologicai components of human compact bone on its torsion properties are quite different from those with regard to its tensile properties. According to Evans and Bang (1966, 1967) osteons (secondary) tend to decrease while interstitial lamellae tend to increase the ultimate tensile strength of human compact bone. They pointed out, however, that it was not the osteons, per se, that decreased the tensile strength of bone but the cement lines surrounding the osteons and their remnants. As in the case of torsion osteons, because of their Haversian canals, lacunae, and canaliculi, also contribute to the reduction of the tensile strength of bone by increasing its porosity or amount of spaces in it.

The probable reason that microfractures can and do occur at the cement lines (Maj and Toajari, 1937 ; Dempster and Coleman, 1961 ; Evans and Bang, 1966. 1967) of compact bone during tensile and bending tests is that they are areas of weakness. As pointed out by Dempster and Coleman, "Weaker structural elements

Table 5. Regional differences in mean maximum and minimum values for torsion properties and histological components of the break area of standardized specimens of adult human femoral compact bone

\begin{tabular}{|c|c|c|c|c|c|c|c|c|c|}
\hline & $\begin{array}{l}\text { Torsion } \\
\text { stress }\end{array}$ & $\begin{array}{l}\text { Shear } \\
\text { modulus }\end{array}$ & $\begin{array}{l}\text { Energy } \\
\text { absorbed } \\
\text { to failure }\end{array}$ & ${ }^{\circ}$ spaces & $\begin{array}{l}\text { "osteon } \\
\text { fragments }\end{array}$ & $\begin{array}{l}\text { o. complete } \\
\text { osteons }\end{array}$ & $\begin{array}{l}\text { "interst. } \\
\text { lamellae }\end{array}$ & $\begin{array}{l}\text { No. osteon } \\
\text { fragments }\end{array}$ & $\begin{array}{c}\text { No. complete } \\
\text { osteons }\end{array}$ \\
\hline Maximum & $\begin{array}{l}M / 3 \\
M . S .\end{array}$ & $\begin{array}{l}\mathrm{M} / 3 \\
\mathrm{M} . \mathrm{S}\end{array}$ & $\begin{array}{l}M / 3 \\
\text { L.S. }\end{array}$ & $\begin{array}{l}\text { M/3 } \\
\text { P.S. }\end{array}$ & $\begin{array}{l}\text { P/3 } \\
\text { A.S. }\end{array}$ & $\begin{array}{l}\mathrm{M} / \mathrm{J} \\
\mathrm{L} . \mathrm{S} .\end{array}$ & $\begin{array}{c}D / 3 \\
A \cdot M . S .\end{array}$ & $\begin{array}{l}P / 3 \\
A . S .\end{array}$ & $\begin{array}{l}M / 3 \\
\text { L.S. }\end{array}$ \\
\hline Minimum & $\begin{array}{c}D / 3 \\
\text { A.L.S. }\end{array}$ & $\begin{array}{c}\text { D/3 } \\
\text { A.L.S. }\end{array}$ & $\begin{array}{c}D / 3 \\
\text { A.L.S. }\end{array}$ & $\begin{array}{l}\mathrm{D} / 3 \\
\mathrm{LS} .\end{array}$ & $\begin{array}{l}M / 3 \\
\text { P.S. }\end{array}$ & $\begin{array}{l}\text { D } / 3 \\
\text { A.S. }\end{array}$ & $\begin{array}{l}\text { P/3 } \\
\text { L.S. }\end{array}$ & $\begin{array}{c}D / 3 \\
\text { A.L.S. }\end{array}$ & $\begin{array}{l}\text { D:3 } \\
\text { P.S. }\end{array}$ \\
\hline
\end{tabular}

$\mathrm{A}=\mathrm{Anterior}, \overline{\mathrm{A}-\mathrm{L}}=\overline{\mathrm{A}} \mathrm{nterolateral,} \mathrm{A} \cdot \mathrm{M}=$ Anteromedial, $\mathrm{L}=$ Lateral, $\mathrm{M}=\mathrm{Medial}, \mathrm{P}=\mathrm{Posterior}, \mathrm{S}=\mathrm{Side}, \mathrm{D} / 3$ 
are the cement lines surrounding osteons and the planes between the lamellae of Haversian systems." The reason why the cement substance is weaker than the other material in compact bone is unknown as the histology of the cement lines is not well understood (Sokoloff, 1973).

It is interesting to note that Evans and Bang (1967) found negative correlations, at the 0.02 and 0.05 significance level, between single (punching) shearing stress and the average area per osteon remnant and the average area per osteon, respectively. This suggests that the larger (area) the osteons or their remnants in the break area the lower is the single shearing stress of adult human compact bone. Unfortunately these results cannot be directly compared with those of the present investigation as the average size (area) of osteons and their remnants was not determined.

\section{REFERENCES}

Abdelnour, T. A. and Evans, F, G. (1976) The mechanical properties of child bone. Proc. 4th New England Bioengineering Conference (Edited by Saha, S.), pp. 97-100. Pergamon Press, Oxford.

Currey, J. D. (1970) The mechanical properties of bone. Clin. Orthop. 73, 210-231.

Dempster, W. T. and Coleman, R. F. (1961) Tensile strength of bone along and across the grain. J. appl. Physiol. 16, $355-360$.

Evans. F. G. (1973) Mechanical Properties of Bone. Thomas, Springfield. Illinois.

Evans, F. G. (1976) Mechanical properties and histology of cortical bone from younger and older men. Anat. Rec. 185, $1-12$.

Evans, F. G. and Bang, S. (1966) Physical and histological differences between human fibular and femoral compact bone. In Studies on the Anatomy and Function of Bone and Joints (Edited by Evans. F. G.). pp. 142-155. Springer, Berlin.

Evans, F. G. and Riolo, M. L. (1970) Reiations between the fatigue life and histology of adult human cortical bone. $J$. Bone Jnt Surg. 53-A, 1579-1586.
Evans, F. G. and Vincentelli, R. (1974) Relations of the compressive properties of human cortical bone to histological structure and calcification. J. Biomechanics ?, $1-10$.

Frost. H. (1960) Measurement of osteocytes per unit volume and volume components of osteocytes and canaliculae in man. Henry Ford Hosp. Med. Bull. 8, $208-211$.

Hazama, H. (1956) Study on the torsional strength of the compact substance of human beings. $J$. Kyoto Pref. Med. Linit. 60, 167-184 (Japanese text, English summary).

Knets, I. V., Pfafrod, G. O.. Saulgozis, Yu. Zh., Laizan. Ya.B. and Yanson, Kh.A. (1973) Degree of deformation and strength of compact bone tissue during torsion. Polymer Mech. 5, 911-918 (Russian text).

Kraus, H. (1968) On the mechanical properties and behavior of human compact bone. In Advances in Biomedical Engineering and Medical Physics (Edited by Levine, S.N.) Vol. 2. Wiley, New York.

Maj, G. and Toajari, E. (1937) Osservazioni sperimentali sul meccanismo di resistenza del tessuto osseo lamellare compatto alle azioni meccaniche. Chir. Organi Mor. 22, $541-557$.

McElhaney. J. H. and Byars, E. F. Dynamic response of biological materials. ASME 65-WA/HUF 9, 1-8.

Evans, F. G. and Bang, S. (1967) Differences and relationships berween the physical properties and the microscopic structure of human femoral, tibial, and fibular cortical bone. Am. J. Anat. 120, 79-88.

Pfafrod, G. O., Knets, I. V., Saulgozis, Yu. Zh., Kregers, A. F. and Yanson, Kh. A. (1975) Age-related changes in the strength of compact bone tissue under torsion. Polymer Mech. 3, 493-503 (Russian text).

Pfafrod, G. O., Saulgozis, Yu. Zh., Knets, I. V. and Yanson. Kh. A. (1972) Experimental determination of the shear modulus of compact bone tissue. Polymer Mech. 4, 697-705 (Russian text).

Rauber, A. A. (1876) Elastizität und Festigkeit der Knochen. Engelmann, Leiprig.

Reilly, D. T. and Burstein, A. H. (1974) The mechanical properties of cortical bone. J. Bone Jnt Surg. 56A. 1001-1022.

Richards, C. W. (1961) Engineering Materials Science. Wadsworth, San Francisco.

Sokoloff. L. (1973) A note on the histology of cement lines. In Perspectices in Biomedical Engineering (Edited by Kenedi. R. M.). pp. 135-138. University Park Press, Baltimore, MD.

Yamada, H. (1970) Strength of Biological Materials. Williams \& Wilkins. Baltimore, MD 